\title{
Study on Mechanical and Thermal Performance of Building Energy-saving Wall with Insulation Materials
}

\author{
Fuzhen Chen ${ }^{1, *}$ \\ ${ }^{1}$ EUniversity of Bath, Claverton Down, Bath BA2 7AY, United Kingdom
}

\begin{abstract}
Sodium alginate and natural fiber were used as modifiers to prepare sodium alginate natural fiber type biological composites. The mechanical properties were characterized by universal testing machine, and the thermal properties were analyzed by conductivity, The effects of wood fiber and straw fiber content on the comprehensive properties of biological composite materials were evaluated by relevant instruments, and the feasibility of biological composite materials as building energy-saving wall insulation materials was evaluated. The results show that the flexural strength, compressive strength and elastic modulus of the composites increase with the increase of wood fiber content. When the wood fiber content is $100 \%$, the mechanical properties of the sample are the best, the flexural strength is $0.573 \mathrm{MPa}$, and the compressive strength is $1.410 \mathrm{MPa}$. The results showed that wood fiber and sodium alginate binder were closely combined and had good wettability. The thermal conductivity of biological composite is $0.078-0.089 \mathrm{w} /$ $(\mathrm{m} \cdot \mathrm{K})$, which means it has good thermal insulation performance and can be used as thermal insulation material for building energy-saving wall. The results show that the properties of the composite can be improved by adding a higher proportion of wood fiber and a certain amount of glyoxal crosslinking agent.
\end{abstract}

\section{Introduction}

According to statistics, the annual greenhouse gas emissions of the construction industry account for about $1 / 3$ of the earth's basic emissions, especially in building insulation materials, the extensive use of fossil and mineral materials has caused serious ecological pollution.[1] At the same time, this kind of insulation material is not renewable, so it is difficult to recycle, resulting in a huge waste of resources. Therefore, in recent years, people begin to work hard to develop clean and sustainable new insulation materials, preparing more effective and environmentally friendly insulation system and avoiding energy waste and environmental pollution.[2] The main research goal of new building insulation materials is to develop low-cost, pollution-free and sustainable natural fiber composite materials, so that its performance is better than that of traditional building insulation materials.

In recent years, in the research and development of natural fiber composite thermal insulation materials, the combination of bio based adhesive and natural fiber has attracted wide attention, such as tannin, lignin, protein and so on.[3] Lignin has a wide range of sources, but it must be heat-treated or chemical treated, which limits its wide application. Tannin is a natural polyphenol widely existing in nature, but only concentrated tannin has good chemical reactivity.[4] Bio resins extracted from sunflower seeds, soybean and other plant proteins can also be used for NFC, but their low water resistance and high oil purification cost limit their application.
Marine organisms can be used as natural polysaccharide precursors in the research of building insulation materials. Sun Yong and others discussed the properties of lightweight composite thermal insulation materials composed of chitosan and sunflower stalk particles.[5] After the research, it was found that the density of the related composite materials was only 150 $\sim 200 \mathrm{~kg} / \mathrm{m} 3$, the thermal conductivity was $0.056 \mathrm{w} /$ $(\mathrm{m} \cdot \mathrm{K})$, and the compressive strength was as high as 2 $\mathrm{MPa}$. It is also found that alginate polysaccharide extracted from brown algae has excellent bioactivity adhesion. At the same time, the sodium alginate does not need heating and can form low toxicity and pollution-free gel in low temperature water environment. The material has become a promising low-cost building insulation material filler.

Nowadays, wood fiber and recycled fiber are the most commonly used natural organic fillers in new building insulation materials. Wood fiber can be obtained from wood waste by mechanical processing, which has the advantages of low cost and good mechanical properties. The use of recycled fiber can greatly reduce the use of pure materials, and the resource waste and environmental pollution can also be reduced by material recycling[6].

The main purpose of this paper is to study the comprehensive utilization performance of alginate natural fiber type of biological composite materials, so as to develop a new environmental protection and sustainable building energy-saving wall insulation 
material.[7] The first is to study the thermal insulation performance of composite materials, and evaluate the thermal insulation performance of composite materials used in building thermal insulation wall. Secondly, the flexural strength and compressive strength of the composite were studied by changing the content of fiber. Finally, the application prospect of alginate natural fiber biological composite in the field of green building materials was analyzed.

\section{Experiment}

The design of raw materials and experimental components, natural fiber selection of wood fiber and rice straw fiber are provided by Puyang Boyuan Fiber Technology Co., Ltd. Commercial sodium alginate, crosslinking agent glyoxal and glutaraldehyde, plasticizer glycerin are provided by Beijing No.1 Chemical Reagent Factory. The wood fiber and rice straw fiber were mixed according to the proportion in Table 1, and water, sodium alginate, plasticizer glycerin, crosslinker glyoxal and other substances were added to obtain sodium alginate natural fiber biological composite sample.

Table 1. Design and Proportion of Experimental Components

\begin{tabular}{|c|c|c|c|c|c|c|c|}
\hline Components & $\begin{array}{c}\text { Wood } \\
\text { fiber } \\
\text { Sample }\end{array}$ & $\begin{array}{c}\text { Straw fiber } \\
/ \mathrm{g}\end{array}$ & Water/g & $\begin{array}{c}\text { Sodium } \\
\text { alginate } \\
/ \mathrm{g}\end{array}$ & Glycerol /g & Glycol /g & $\begin{array}{c}\text { Base material/ } \\
\text { Fiber dry mass } \\
\text { ratio }\end{array}$ \\
\hline CM-0/100 & -- & 64 & 224 & 16 & 4 & -- & 0.31 \\
\hline CM-50/50 & 32 & 32 & 224 & 16 & 4 & -- & 0.31 \\
\hline CM-60/40 & 38.4 & 25.6 & 224 & 16 & 4 & -- & 0.31 \\
\hline CM-70/30 & 44.8 & 19.2 & 224 & 16 & 4 & -- & 0.31 \\
\hline CM-100/0 & 64 & -- & 224 & 16 & 4 & -- & 0.31 \\
\hline CM-60/40G & 38.4 & 25.6 & 224 & 16 & 4 & 8 & 0.31 \\
\hline
\end{tabular}

\subsection{Preparation of biological composite materials}

Firstly, different proportions of wood fiber and rice straw fiber were added into the steel barrel in batches, and the mixture was evenly stirred. Secondly, preparing sodium alginate solution in three steps, (1) Preparation of glycerol / water solution; (2) introduction of crosslinking agent into the solution; (3) addition of sodium alginate and continuous stirring for $2 \mathrm{~min}$ at $200 \mathrm{R} / 2 \mathrm{~min}$. Then, the prepared fibers were immersed in sodium alginate solution and stirred for $2 \mathrm{~min}$ at the speed of $20 \mathrm{R} / 2 \mathrm{~min}$. Then, the wet fiber was put into a $160 \mathrm{~mm} \times 400 \mathrm{~mm}$ metal mold, extruded by hot pressing device under $5 \mathrm{MPa}$ pressure, and then the sample was placed at $70{ }^{\circ} \mathrm{C}$ for 2GH. Finally, the samples were stored in a climate chamber with $20{ }^{\circ} \mathrm{C}$ and $50 \%$ relative humidity for 10 days. After reaching the mass balance, two samples of each formula were put into a ventilated oven at $105^{\circ} \mathrm{C}$ for 24 hours.

\subsection{Characterization of Biological Composites}

\subsubsection{Thermal Performance Test}

The thermal conductivity, overflow rate and diffusivity of alginate natural fiber bio-composites were measured by using Netzsch LFA427 laser thermal conductivity meter.

\subsubsection{Mechanical Performance Test}

According to "GB/T1928-2009 general rules for physical and mechanical test methods of wood", the stress-strain curves of the specimens were measured by
INSTRON5966 universal testing machine. The loading pressure is $2.5 \mathrm{kN}$, the loading rate is $2 \mathrm{~mm} / \mathrm{min}$, and the sample size is $160 \mathrm{~mm} \times 40 \mathrm{~mm} \times 40 \mathrm{~mm}$. According to the test specification, the compressive and bending properties of the composites were tested. During the test, the loading pressure is $10 \mathrm{kN}$, the loading rate is $10 \mathrm{~mm} /$ $\mathrm{min}$, and the sample size is $80 \mathrm{~mm} \times 40 \mathrm{~mm} \times 40 \mathrm{~mm}$.

\section{Results and Discussion}

\subsection{Drying Properties of Biological Composites}

The average density of the samples was $(970 \pm 10) \mathrm{KG} /$ $\mathrm{m} 3$ when the samples were placed in a climate chamber with relative humidity of $50 \%$ and temperature of $20{ }^{\circ} \mathrm{C}$. Then the samples were dried by natural convection in the climate chamber until the quality of the samples was stable. Fig. 1 shows the change trend curve of sample mass with drying time. It can be seen from Figure1 that the higher the content of lignocellulosic fiber is, the more the mass loss of the bio-composites is. In Fig.1, after drying for $250 \mathrm{~h}$, except $\mathrm{cm} 0 / 100$, the mass of other groups of bio-composites reached equilibrium. Therefore, rice straw fiber has higher hydrophilicity than wood. In Figure1, the curve CM60 / 40 shows the change of the mass of the sample without glyoxal addition with the drying time, and the curve CM60 / 40G shows the change of the mass of the sample with glyoxal addition with the drying time. From the change trend of the curve, it is found that the presence of crosslinking agent significantly accelerates the drying process of the biological composite. 


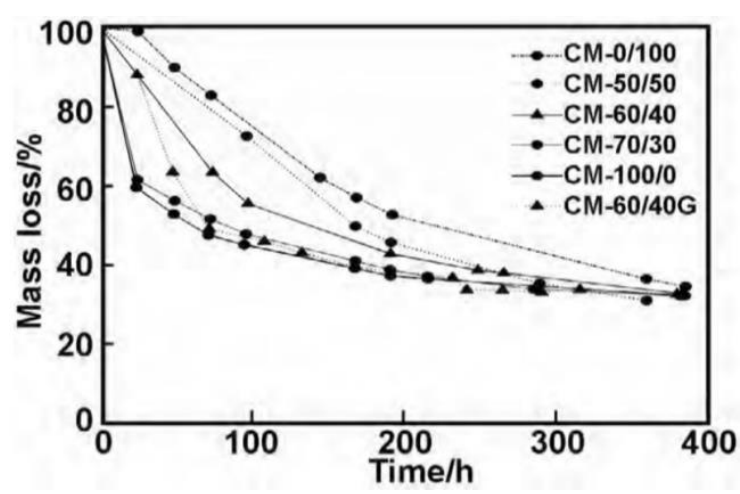

Fig.1. Variation Curve of Sample Mass with Drying Time

\subsection{Bending Properties of Biological Composites}

Table 2 shows the change of flexural properties (modulus of elasticity, flexural strength and maximum flexural strain) of biological composite samples with the content of wood fiber / rice straw fiber. It can be seen from table 2 that the flexural strength and elastic modulus of the biological composite material increase with the increase of the content of wood fiber. When the content of wood fiber is $100 \%$, the flexural strength and elastic modulus of the sample are the maximum, which are $0.573 \mathrm{MPa}$ and $17.580 \mathrm{MPa}$ respectively. The maximum bending strain of bio-composites decreases with the increase of wood fiber. When the content of wood fiber is $100 \%$, the maximum bending strain decreases to $3.560 \mathrm{MPa}$. Therefore, from the perspective of mechanics, the addition of wood fiber can play a role in strengthening the matrix material, thus significantly improving the stiffness of the biological composite.

Table 2 .Relationship between Flexural Properties and Fiber Content of Biological Composites

\begin{tabular}{|c|c|c|c|}
\hline Pexformance & $\begin{array}{c}\text { Elastic } \\
\text { Modulus } \\
E_{c} / \mathrm{Mpa}\end{array}$ & $\begin{array}{c}\text { Bending } \\
\text { Strength, } \\
\sigma_{c} / \mathrm{MPa}\end{array}$ & $\begin{array}{c}\text { Maximum } \\
\text { Bending } \\
\text { Strain, } \varepsilon_{c} \\
/ \mathrm{MPa}\end{array}$ \\
\hline $\mathrm{CM}-0 / 100$ & 4.680 & 0.083 & 12.230 \\
\hline $\mathrm{CM}-50 / 50$ & 9.860 & 0.272 & 6.340 \\
\hline $\mathrm{CM}-60 / 40$ & 10.330 & 0.280 & 5.440 \\
\hline $\mathrm{CM}-70 / 30$ & 14.760 & 0.395 & 5.010 \\
\hline $\mathrm{CM}-100 / 0$ & 17.58 & 0.573 & 3.56 \\
\hline $\mathrm{CM}-60 / 40 \mathrm{G}$ & 13.41 & 0.437 & 5.23 \\
\hline
\end{tabular}

\subsection{Compressive Properties of Biological Composites}

Table 3 shows the relationship between compressive properties and fiber content of biological composites. It can be seen from table 3 that the compressive strength and elastic modulus of the bio composites increase with the increase of wood fiber content, similar to the bending properties. When the content of wood fiber is $100 \%$, the compressive modulus and compressive strength of the bio-composites are the highest, which are $1.410 \mathrm{MPa}$ and $21.980 \mathrm{MPa}$ respectively. At the same time, it can be seen from table 3 that the addition of crosslinking agent glyoxal can increase the compressive strength and elastic modulus of the biological composite. Taking cm60 / 40 sample as an example, the elastic modulus and compressive strength of the composite increased by $21 \%$ and $16 \%$ respectively after adding glyoxal. Because of the existence of crosslinking agent, the mechanical properties of the biological composite are improved obviously, and its rigidity is also improved to a certain extent.

Table 3 .Relationship between Compressive Properties and Fiber Content of Biological Composites

\begin{tabular}{|c|c|c|}
\hline & $\begin{array}{c}\text { Elastic Modulus } \\
E_{c} / \mathrm{Mpa}\end{array}$ & $\begin{array}{c}\text { Compressive } \\
\text { Strength, } \sigma_{c} / \mathrm{MPa}\end{array}$ \\
\hline $\mathrm{CM}-0 / 100$ & 2.560 & 0.406 \\
\hline $\mathrm{CM}-50 / 50$ & 13.890 & 0.685 \\
\hline $\mathrm{CM}-60 / 40$ & 16.970 & 0.719 \\
\hline $\mathrm{CM}-70 / 30$ & 18.630 & 0.857 \\
\hline $\mathrm{CM}-100 / 0$ & 21.980 & 1.410 \\
\hline $\mathrm{CM}-60 / 40 \mathrm{G}$ & 19.420 & 0.834 \\
\hline
\end{tabular}

\subsection{Micro morphology of biological composites}

Figure 2 shows the micro morphology of CM-100 / 0 biological composite. According to the above experimental data, the bending and compressive properties of CM-100 / 0 bio-composites with $100 \%$ wood fiber content are the best, so the tearing surface of CM-100 / 0 bio-composites is selected for SEM analysis. It can be clearly seen from Figure 2 that there is no aggregation phenomenon of wood fiber, and the wood fiber and sodium alginate binder are closely combined. Even on the tearing surface, there is no microcrack between the wood fiber and sodium alginate binder.[8] The wettability between wood fiber and sodium alginate binder was good, and the binder still tightly wrapped the wood fiber at the fracture of wood fiber, which also explains the reason why the flexural and compressive properties of the bio composites with $100 \%$ wood fiber content are the best.

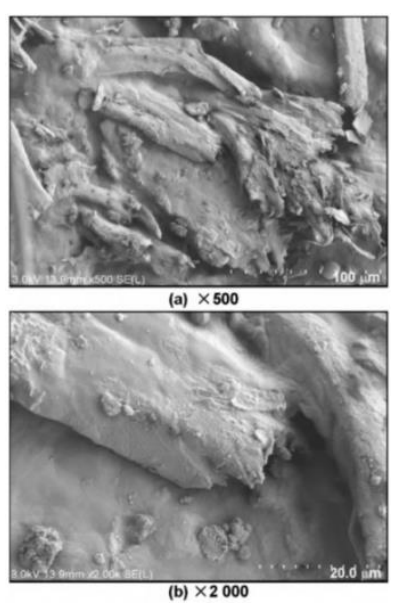

Fig.2. SEM of CM-100 / 0 Biological Composite Sample 


\subsection{Thermal properties of biological composites}

When the thermal conductivity of a material is less than $0.1 \mathrm{~W} /(\mathrm{m} \cdot \mathrm{K})$, it is considered as heat insulation. It can be seen from Figure 4 that the thermal conductivity of the biological composite material prepared in this paper is between 0.078 and $0.089 \mathrm{w} /$ $(\mathrm{m} \cdot \mathrm{K})$, so the biological composite material has good thermal insulation ability, and it can be used as the thermal insulation material of building energy-saving wall.The thermal conductivity of the biological composite material decreases first and then increases with the increase of the content of wood fiber. When the content of wood fiber is $60 \%$, the lowest conductivity of the material is $0.078 \mathrm{~W} /(\mathrm{m} \cdot \mathrm{K})$. Compared with other building energy-saving thermal insulation materials with the same density (300 $350 \mathrm{~kg} / \mathrm{m} 3)$, the thermal insulation performance of sodium alginate natural fiber biological composite material is better.

The results show that the diffusivity of the sample without wood fiber is $310 \times 10-7 \mathrm{~m} 2 / \mathrm{s}$, while the diffusivity of the sample with $100 \%$ wood fiber is 174 $\times 10-7 \mathrm{~m} 2 / \mathrm{s}$, which can be seen that the addition of wood fiber can significantly reduce the diffusivity of the composite and the heat transfer capacity of the biological composite, making it performs better in thermal insulation.

When the content of wood fiber is between $50 \%$ and $60 \%$, the overflow rate of biological composite material has an abnormal increasing trend. When the content of wood fiber is $100 \%$, the spillover rate of biological composite materials can reach $183 \mathrm{~W} \cdot \mathrm{s} 1 /$ $2 /(\mathrm{m} 2 \cdot \mathrm{K})$, while the spillover rate of biological composite materials without wood fiber is only $149 \mathrm{~W} \cdot \mathrm{s} 1 / 2 /(\mathrm{m} 2 \cdot \mathrm{K})$. It can be seen that adding wood fiber can significantly improve the spillover rate of materials, which can help to improve the thermal comfort of building structure. In addition, the addition of glyoxal crosslinker has a certain effect on the thermal conductivity of the bio-composites.[9] Therefore, adding a higher proportion of wood fiber and an appropriate amount of glyoxal cross-linking agent can improve the thermal insulation performance of biological composite materials, and better the thermal comfort of building envelope.

\section{Conclusion}

In this paper, sodium alginate natural fiber bio-composites were prepared and the doping ratio of wood fiber and rice straw fiber was studied in detail. The mechanical properties of the bio-composites were studied by compression experiment and bending experiment. Besides, the thermal conductivity, diffusivity and overflow rate of the bio-composites were tested by conductivity meter theory. The conclusion is as follows.
(1)The results showed that the higher the content of lignocellulose is, the more the mass loss of the bio-composites is. The presence of crosslinking agent significantly accelerated the drying process of the bio-composites.

(2)The test results of mechanical properties show that the flexural strength, compressive strength and elastic modulus of the composite increase with the increase of wood fiber content. When the content of wood fiber is $100 \%$, the mechanical properties of the sample are the best, and the flexural strength and compressive strength reach $0.573 \mathrm{MPa}$ and $1.410 \mathrm{MPa}$ respectively.[10] Adding proper amount of glyoxal crosslinking agent can improve the rigidity and mechanical properties of biological composites.

(3)SEM analysis showed that the bending and compressive properties of the samples with $100 \%$ wood fiber content were the best, and the wood fiber and sodium alginate binder were closely combined in the samples, and the wettability between them was good.

(4)The thermal performance research results show that the prepared bio-composite has good thermal insulation ability, and its thermal conductivity is between 0.078 and $0.089 \mathrm{~W} /(\mathrm{m} \cdot \mathrm{K})$, which can be used as the thermal insulation material of building energy-saving wall. The heat transfer and heat preservation properties of the composites were improved by adding higher proportion of wood fiber and proper amount of glyoxal crosslinking agent.

\section{References}

1. Amjad Almusaed,Asaad Almssad,Raad Z. Homod,Ibrahim Yitmen. Environmental Profile on Building Material Passports for Hot Climates[J]. Sustainability,2020,12(9).

2. Raluca Fernea,Iacob Florea,Daniela Lucia Manea,Petru Păşcuță,Daniela Roxana Tămaş-Gavrea. X-ray diffraction study on new organic- natural building materials[J]. Procedia Manufacturing,2018,22. 、

3. Wu Xinyu, Ma Benhe. Discussion on the Selection of Natural Materials in Interior Space Design[J]. Journal of Qiqihar University (Phi\& Soc Sci),2017(11):159-161.

4. Yang Chunwei. The Quality Analysis of Natural Building Materials in Xingjia Wan Open Card Section[J]. Water Sciences and Engineering Technology,2017(04):94-96.

5. Wang Chunhong, Lu Chao. Study on Performance of NFPR in Building Application[J]. China Textile Leader,2019(S1):90-94.

6. Qu Zhi, Yin Yong. Application of Natural Degradable Materials in Building Field [J]. Information Recording Materials,2019,20(09):26-27. 
7. An Chang, Meng Xiaoli. Thermal Stability Analysis of Building Polymer Materials Based on Finite Element Method [J]. Synthetic Materials Aging and Application,2020,49(06):103-106+75.

8. Zhang Xin. Energy-saving and Thermal Insulation Materials with Testing Technology of Building Exterior Wall[J]. Journal of Ceramics, 2020(08):90-91.
9. Zhao Runli. The Application Technology of STP Vacuum Insulation Board Building Exterior Wall External Insulation[J]. Shanxi Architecture,2020,46(13):138-139+155.

10. Wen Zhelin. Thermal and Moisture Characteristics of Exterior Wall Material and Its Influence on Building Heating Energy Consumption [D]. Harbin Institute of Technology,2019. 